\title{
ANALISIS DAYA TARIK WISATA EMBUNG MANAJAR DI KABUPATEN BOYOLALI JAWA TENGAH
}

\author{
Made Prasta Yostitia Pradipta \\ Sekolah Tinggi Pariwisata Sahid Surakarta \\ madeprastapradipta@gmail.com
}

\begin{abstract}
With local tourism, it can help and empower human resources and the economy of the community around these attractions. Therefore, many areas are developing potential tourist attractions to be used as tourist attractions. One of them is the Boyolali area in Central Java Province which has a must-visit tourist destination, namely Embung Manajar. This study was conducted with the aim of identifying the components of the Embung Manajar tourist attraction in Boyolali based on 4A (Attraction, Amenity, Accessibility, and Ancillary Service). This study uses a type of qualitative research. This method emphasizes the observation of phenomena directly through field observations. From the research results, the attraction component is strong enough to attract visitors, but the feasibility of amenities and accessibility in this reservoir is still lacking, and there is no special organization for good management from the community. It is hoped that with this research, it can support managers and the surrounding community in an effort to develop Embung Manajar tourism in the future.
\end{abstract}

Keywords: Tourist Attraction, Embung Manajar

\section{PENDAHULUAN}

Sektor pariwisata saat ini merupakan bentuk bisnis global yang menjanjikan karena dapat mendorong pertumbuhan ekonomi dunia melalui pergerakan wisatawannya. Pariwisata telah menjadi sektor komersial penting di banyak negara berkembang dalam beberapa tahun terakhir (Steves et al., 2011). Pariwisata di Indonesia dari tahun ke tahun sudah mulai berkembang pesat dan memiliki daya tarik tersendiri untuk memikat para wisatawan. Pariwisata lokal saat ini mampu untuk berkembang dan bersaing dengan pariwisata lain yang berada di daerah maupun di perkotaan. Dengan adanya pariwisata lokal dapat membantu dan juga memberdayakan sumber daya manusia dan perekonomian masyarakat sekitar obyek wisata tersebut (Nundy et al., 2021). Oleh karena itu, banyak daerahdaerah yang sedang mengembangkan objek wisata yang potensial untuk dijadikan tempat wisata. Salah satunya adalah daerah Boyolali yang berada di Provinsi Jawa Tengah memiliki destinasi wisata yang wajib dikunjungi yaitu Embung Manajar. 
Embung merupakan bangunan konservasi air berbentuk cekung yang berfungsi sebagai penampungan air hujan. Embung manajar merupakan objek wisata baru yang memiliki potensi daya tarik yang perlu dikembangkan dengan baik agar dapat menarik minat wisatawan untuk berkunjung ulang. Embung ini berada di Dusun Samiran, Selo, Boyolali, Jawa Tengah. Embung ini memiliki lanskap yang elok, karena menghadap langsung dengan gunung merapi. Embung Manajar terletak di lereng sebelah selatan Gunung Merbabu. Menurut peta topografi Google Maps, embung ini berada di ketinggian sekitar seribu tujuh ratus meter di atas permukaan laut (mdpl).

Embung ini dibangun bermula karena desa Samiran kekurangan air untuk perairan pertanian, kemudian warga manajar mengusulkan pembangunan embung untuk pengairan kepada Kepala Desa. Namun, setelah pembangunan selesai, embung manajar mulai dijelajahi oleh wisatawan hingga akhirnya menjadi trending topic sebagai destinasi wisata. Kemudian, mulai adanya keterlibatan warga dalam mengelola objek Embung Manajar dan dijadikan sebagai objek wisata dengan tiket retribusi senilai lima ribu rupiah, retribusi ini dialokasikan untuk kegiatan perbaikan fasilitas serta akses jalan dan pembagian jatah untuk tiap anggota dari warga sekitar yang berpartisipasi mengelola embung ini. Banyak obyek wisata yang patut dan menarik untuk dikunjungi termasuk obyek wisata Embung Manajar. Akan tetapi, belum adanya pengembangan berkelanjutan yang ada di embung manajar membuat Embung manajar dinilai kurang mendapat perhatian dari wisatawan dan belum dikenal luas oleh wisatawan dan masih kalah tenar dengan obyek wisata lain di Desa Samiran, Selo, Boyolali.

Analisis mengenai daya tarik wisata sudah banyak di teliti oleh peneliti lain (Ariningsiha \& Nugrohoa, 2015; Pradipta, 2021; Pradipta et al., 2018; Rif'an, 2018; Zheng et al., 2021). Pada umumnya berfokus pada wisata alternatif lain (Terzidou, 2020; Valentina, 2015). Faktanya, untuk daya tarik wisata butuh adanya penggalian potensi yang ada di obyek wisata (Mauludin, 2017). Salah satu aspek yg luput dari kajian itu adalah menganalisis daya tarik wisata untuk dapat dikembangkan (Abdulhaji \& Yusuf, 2016). Tujuan dari penelitian ini yaitu untuk menggali atau mengidentifikasi lalu menganalisis potensi komponen daya tarik yang dapat dikembangkan di Embung Manajar. Dengan adanya penelitian ini diharapkan dapat memberikan dampak positif untuk objek Embung Manajar ke depannya. Dengan munculnya objek wisata embung ini, dapat memberi dampak positif untuk membantu perekonomian warga sekitar seperti membangun warung kecil, tukang parkir, dan jasa ojek motor. 


\section{Komponen Daya Tarik}

Daya tarik merupakan hal penting dalam menarik minat wisatawan untuk berkunjung (Pradipta, 2018). Karena dengan adanya daya tarik yang unik dan menarik, tentunya dapat menjadi dorongan minat dan kesan tersendiri bagi wisatawan untuk mendatangi tempat tersebut. Suatu daerah dapat menjadi tujuan wisata apabila kondisinya mendukung untuk dikembangkan (Mauludin, 2017). Apa yang dapat dikembangkan dapat menjadi modal suatu daya tarik wisata. Untuk menggali suatu potensi pariwisata di suatu daerah perlu menerapkan pada pedoman apa yang dicari oleh wisatawan. Modal atraksi yang dapat menarik minat kedatangan wisatawan ada tiga, yaitu atraksi wisata alami, atraksi wisata budaya, dan atraksi buatan manusia. Modal tersebut dapat digunakan sebagai acuan pengembangan atraksi suatu destinasi, sehingga dapat menahan wisatawan untuk tinggal bahkan pada kesempatan lain untuk berkunjung kembali. Keberadaan atraksi menjadi alasan dan motivasi wisatawan untuk mengunjungi daerah tujuan wisata.

Penelitian ini mengadopsi beberapa teori yang relevan mengenai komponen daya tarik wisata. Menurut Cooper dkk (1995:81), terdapat empat komponen yang harus dimiliki dalam sebuah daya tarik wisata, antara lain :

\section{Atraksi (Attractions)}

Merupakan atribut dari daerah tujuan wisata yang meliputi sesuatu yang dapat menarik wisatawan dan setiap destinasi tentunya memiliki daya tarik, baik berupa alam, masyarakat, maupun budayanya.

2. Aksesbilitas (Accesbilities)

Merupakan atribut akses wisatawan domestik maupun mancanegara agar dengan mudah mencapai tujuan ke tempat wisata baik secara internasional maupun akses terhadap tempat wisata pada sebuah destinasi, seperti ketersediaan alat transportasi yang memadai.

3. Amenitas (Amenities)

Merupakan atribut amenitas yang dapat menjadi salah satu syarat dari daerah tujuan wisata agar wisatawan dapat merasa betah dan nyaman untuk tinggal lebih lama di sebuah destinasi, seperti ketersediaan fasilitas akomodasi hotel atau penginapan, agen perjalanan wisata, dsb.

4. Pelayanan tambahan (Ancillary services)

Merupakan atribut sumber daya manusia, sistem serta kelembagaannya berupa lembaga pariwisata yang dapat mendukung sebuah destinasi layak untuk dikunjungi. Aspek kelembagaan tersebut seperti dukungan lembaga keamanan, lembaga pariwisata sebagai pengelola destinasi, serta 
lembaga pendukung lainnya yang dapat menciptakan kenyamanan untuk wisatawan. Lebih lanjut, Yoeti (1996:177) menambahkan bahwa supaya suatu daya tarik daerah tujuan wisata layak dikunjungi oleh wisatawan potensial, setidaknya memiliki tiga indikator meliputi :

1. Something to see (sesuatu untuk dilihat), artinya di daerah tersebut harus memiliki objek wisata dan atraksi wisata yang berbeda dan tidak dimiliki oleh daerah lain.

2. Something to do (sesuatu untuk dilakukan), artinya selain yang dapat dilihat dan disaksikan di daerah tersebut, maka diperlukan ketersediaan fasilitas rekreasi yang dapat membuat wisatawan betah untuk tinggal lebih lama di tempat tersebut.

3. Something to buy (sesuatu untuk dibeli), di daerah tersebut harus menyediakan fasilitas untuk berbelanja (shopping), terutama souvenir dan kerajinan masyarakat setempat untuk dibawa ke tempat asal wisatawan.

\section{METODE PENELITIAN}

Dalam penelitian ini peneliti menggunakan metode penelitian kualitatif. Penelitian ini dilakukan oleh penulis yang berlokasi di Embung Manjar yang beralamat di Dusun IV, Samiran, Selo, Kabupaten Boyolali,
Jawa Tengah, kode pos 57363. Informan kunci yang digunakan sebagai subjek penelitian yaitu Bapak Ahmad Salip Mutakhin selaku pengelola Embung Manajar. Data yang digunakan dalam penelitian ini adalah data primer dan data sekunder. Dalam penelitian ini, peneliti menggunakan teknik pengumpulan data yaitu: observasi, wawancara, studi pustaka dan dokumentasi. Teknik analisis yang digunakan penelitian ini adalah triangulasi data yang dijabarkan melalui deskriptif kualitatif.

\section{HASIL DAN PEMBAHASAN \\ Identifikasi Komponen Daya Tarik Wisata Embung Manajar}

Wisata Embung Manajar memiliki potensi daya tarik potensial yang dapat dikembangkan. Menurut Cooper (1995), suatu komponen daya tarik destinasi yang harus dimiliki yaitu meliputi :

\section{Atraksi}

Menurut Kurniawati (2019), salah satu dasar yang dimiliki daya tarik suatu destinasi wisata adalah objek wisata alam yang memiliki daya tarik tinggi keindahan alam seperti pegunungan, pantai, sungai, dll. Atraksi utama yang terdapat di Embung Manajar yakni nature resources (alami) yang menjadi something to see Embung Manajar yaitu pemandangan alam Gunung Merapi berupa wisata buatan yaitu Embung Manajar. Pengunjung dapat mengabadikan foto dan menikmati langsung wisata buatan ini yang 
letaknya tepat berada di tengah pemandangan gunung merapi dengan suasana udara yang sejuk. Suasana embung yang sejuk dan tenang sangat cocok untuk dijadikan tempat tujuan wisata melepas penat. Something to see lainnya yang dapat dinikmati pengunjung yaitu menyaksikan pemandangan sunset dan sunrise di Embung Manajar.

Berdasarkan hasil observasi tersebut, dapat didukung dengan pernyataan Bapak Salip selaku pengelola mengenai daya tarik, sebagai berikut :

"Awalnya sebelum tahun 2015, pengunjung ke Selo pada tanya apa tho wisatanya di Selo?. Memang kalau di Selo itu yang dijual cuma view Merapi dan Merbabu".

Dengan pernyataan tersebut dapat disimpulkan bahwa potensi daya tarik yang memikat minat pengunjung di Embung Manajar adalah pesona pemandangan alam gunung merapi dengan suasana udara yang sejuk dengan letak Embung Manajar yang berada tepat di tengah pemandangan Gunung Merapi, sehingga dapat menjadi ciri khas tersendiri yang hanya dimiliki oleh objek Embung Manajar dan dapat berpotensi dijadikan objek wisata unggulan di Boyolali, apabila dilakukan upaya yang tepat dalam mengembangkan destinasi tersebut, dan perlunya menekankan pada pelestarian lingkungan sekitar kawasan Embung Manajar dengan menjaga kebersihan lingkungan kawasan agar tidak merusak ekosistem alam. Di dalam upaya pengembangan atraksi perlu menerapkan konsep kreatif serta inovatif dengan cara menghasilkan ide baru untuk memperindah objek wisata Embung Manajar.

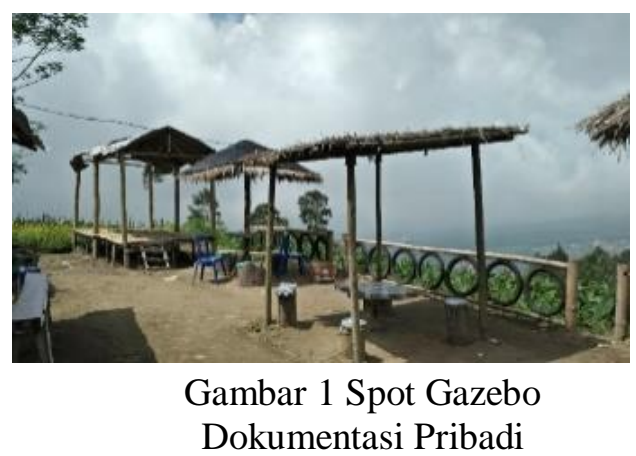

\section{Amenitas}

Fasilitas dalam suatu objek wisata merupakan komponen yang sangat penting dalam pengembangan destinasi wisata ke depannya. Fasilitas merupakan bagian dari fasilitas pendukung dalam memenuhi kebutuhan fisik dasar wisatawan (gambar 1). Menurut hasil observasi peneliti, fasilitas yang sudah tersedia hingga saat ini diantaranya :

\section{Gazebo}

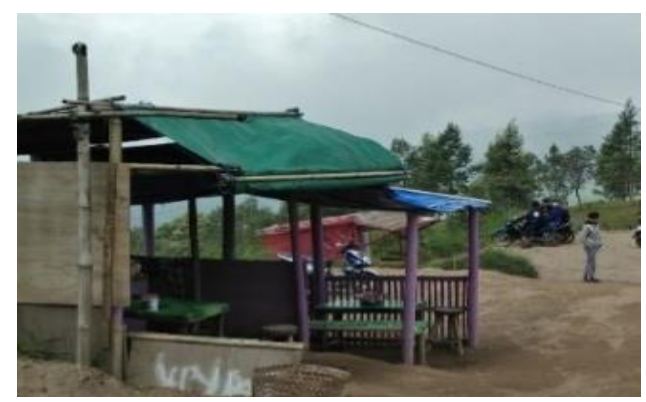

Gambar 2 Spot Gazebo

Dokumentasi Pribadi

Pengunjung dapat menikmati panorama Gunung Merapi dan 
Embung Manajar dengan bersantai di gazebo yang telah disediakan.

\section{Tempat Duduk}

Pengunjung dapat beristirahat dan menikmati pemandangan dan udara sejuk dengan duduk di fasilitas yang telah disediakan.

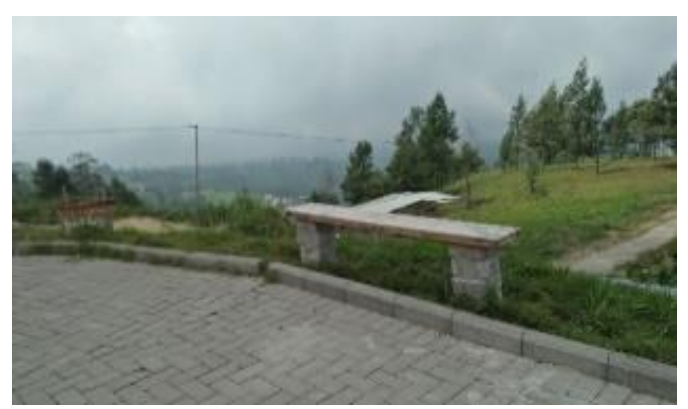

Gambar 3 Pemandangan di Embung Manajar

Dokumentasi Pribadi

3. Warung

Warung-warung kecil yang dibangun oleh warga sekitar, pengunjung dapat membeli makanan dan minuman yang dijual oleh warga.

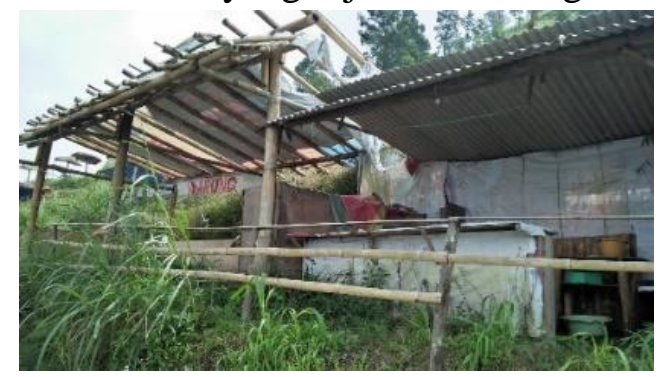

Gambar 4 Warung di Sekitar Embung Manajar

Dokumentasi Pribadi

\section{Tempat Sampah}

Tempat sampah sudah disediakan tempat sampah di beberapa titik, sehingga pengunjung tidak membuang sampah sembarangan.

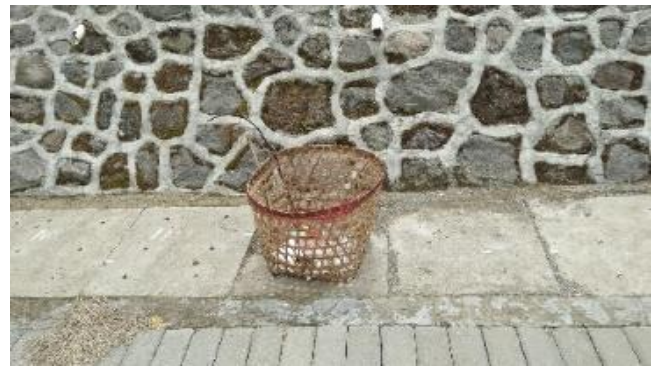

Gambar 4 Tempat Sampah Dokumentasi Pribadi

5. Lahan parkir
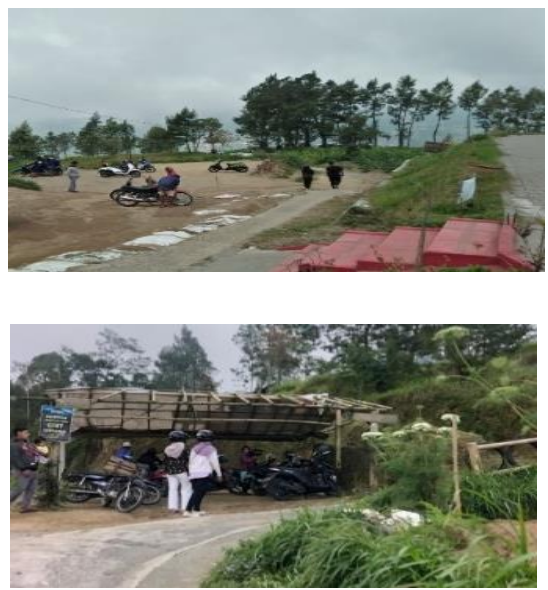

Gambar 5 dan 6 Lahan Parkir Dokumentasi Pribadi

6. Loket tiket dan pusat informasi

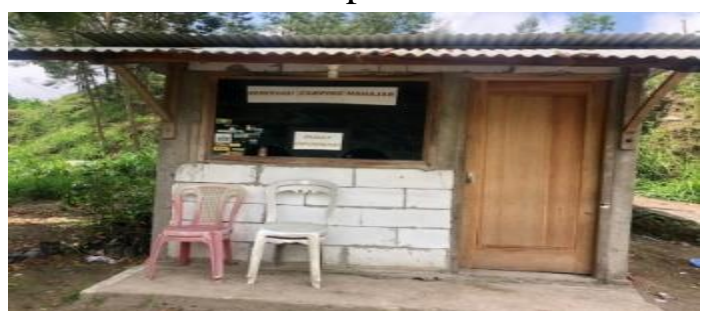

Gambar 7 Loket Tiket

Dokumentasi Pribadi

7. Jasa Ojek

Pengunjung dapat menggunakan fasilitas jasa ojek yang telah disediakan dengan tarif Rp.30.000 untuk naik dan turun embung. 


\section{Toilet umum}

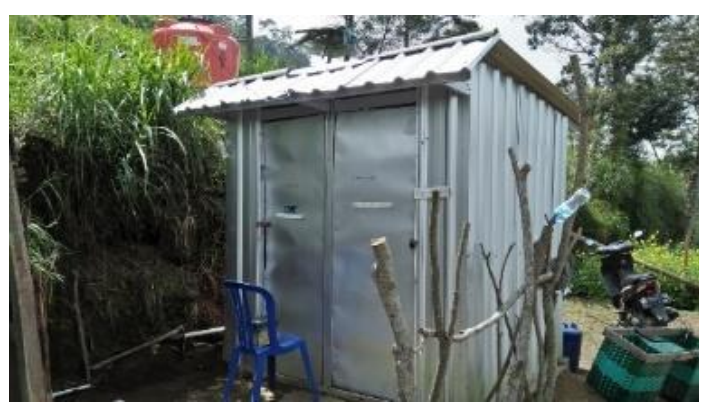

Gambar 8 Toilet Umum Dokumentasi Pribadi

9. Tersedianya jaringan komunikasi

10. Gardu pandang, pengunjung dapat berfoto dan menikmati pemandangan disini. Letak spot ini berada di atas embung.

11. Persewaan alat camping, pengunjung dapat menggunakan fasilitas ini ketika ingin melakukan camping di Embung Manajar. Kegiatan camping ini hanya dapat dilakukan khusus di hari Sabtu-Minggu saja.

12. Tersedianya areal perkemahan atau camping, wisatawan dapat melakukan kegiatan perkemahan di areal yang sudah disediakan di Embung Manajar.

13. Fotografer, pengunjung dapat menggunakan jasa fotografer yang ada di embung untuk mengabadikan foto.

14. Berkuda, fasilitas ini dapat digunakan pengunjung ketika hari weekend (Sabtu-Minggu) saja.

15. Sarana olahraga, pengunjung dapat menggunakan objek sebagai sarana olahraga seperti jogging dan bersepeda gunung.

16. Tersedianya himbauan peringatan

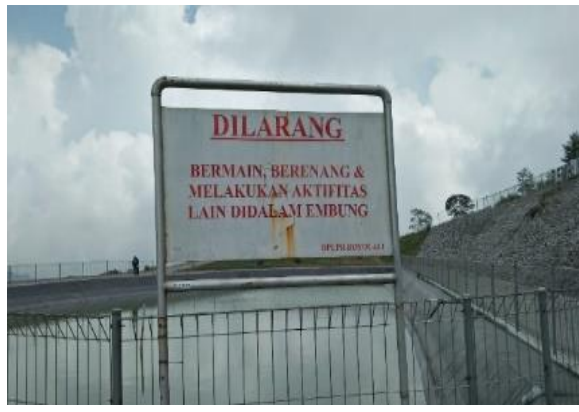

Gambar 9 Tanda Larangan

Melakukan Kegiatan Lain Selain

Pariwisata

Dokumentasi Pribadi

Namun masih terdapat kelemahan dalam ketersediaan fasilitas penunjang di wisata Embung Manajar seperti :

1. Belum tersedianya listrik dan air bersih

2. Belum adanya fasilitas untuk menjaga kebersihan sesuai protokol kesehatan,

3. Penataan warung-warung kecil yang belum rapi dan masih ada beberapa warung yang tidak terpakai sehingga terbengkalai dan terlihat kumuh.

4. Jumlah toilet umum hanya ada dua, sehingga belum bisa memenuhi standar kebutuhan wisatawan sesuai dengan jumlah kunjungan wisatawan

5. Belum adanya pusat perbelanjaan seperti toko souvenir

6. Belum adanya sarana ibadah seperti mushola

7. Belum adanya layanan fasilitas kesehatan

8. Belum adanya rambu-rambu peringatan kebersihan 
9. Belum adanya pos penjagaan

10. Belum adanya akomodasi penginapan seperti homestay ataupun villa di kawasan Embung Manajar

\section{Aksesbilitas}

Embung Manajar terletak di

Desa Samiran, Selo, Kabupaten Boyolali, Jawa Tengah. Akses menuju lokasi ini dapat ditempuh melalui jalur darat. Lokasi ini terletak di jalan Boyolali-Magelang dan berjarak sekitar 23 kilo meter yang dapat ditempuh sekitar 45 menit dari pusat kota Boyolali. Moda transportasi pribadi menjadi pilihan utama, karena belum ada transportasi umum yang dapat digunakan untuk menuju kawasan. Berdasarkan hasil observasi peneliti, dapat disimpulkan bahwa lokasi menuju Embung Manajar tidak dapat ditempuh menggunakan kendaraan umum, karena akses jalan yang terlalu berkelok dan sangat tidak memungkinkan angkutan penumpang umum seperti bus untuk melewati akses ini, sehingga hanya dapat diakses menggunakan kendaraan pribadi.

Akses jalan raya utama penghubung dari Pusat Kota Boyolali menuju daerah Selo telah dirasa cukup. Hal ini dapat dilihat dari jalan raya yang telah diaspal hingga daerah Cepogo, sementara itu daerah Cepogo hingga Selo dicor beton. Dilengkapi dengan penerangan jalan, pembatas jalan, convex mirror (cermin lalu lintas), dan petunjuk lalu lintas yang disediakan oleh jasa marga. Namun, untuk akses jalan desa menuju embung masih memerlukan perbaikan, akses ini berjarak sekitar satu kilo meter mulai dari pintu masuk loket. Lebar jalan tidak terlalu luas dan hanya mampu dilalui kendaraan roda dua, akses jalan menggunakan cor semen dan ada yang berlubang, belum ada pembatas jalan, kurangnya rambu himbauan, belum ada penunjuk jalan dan medannya terlalu menanjak. Mengenai kelemahan aksesbilitas Embung Manajar tersebut diungkapkan oleh Bapak Salip selaku pengelola dalam kutipan berikut :

"Hingga saat ini pengunjung mengeluh mengenai akses jalan yang sempit dan menanjak."

Untuk mendukung keamanan dan keselamatan pengunjung menuju lokasi, warga sekitar telah menyediakan jasa ojek motor dengan tarif Rp.30.000,00 mulai berangkat sampai pulang. Untuk pengunjung yang membawa kendaraan roda dua dapat melintas langsung menuju objek Embung Manajar. Namun, perlu memastikan kendaraan kuat dan aman untuk dibawa menanjak, mengingat medan menuju lokasi yang terlalu ekstrim. Namun, apabila pengunjung tidak berani untuk membawa kendaraan motor sampai embung, pengunjung juga dapat menggunakan jasa ojek. Untuk pengunjung yang membawa kendaraan roda empat hanya dapat melintas sampai dekat loket tiket masuk saja, karena akses jalan menuju embung hanya dapat 
dilintasi kendaraan bermotor. Setelah itu, pengunjung dapat menggunakan jasa ojek yang disediakan warga sekitar.

Pihak pengelola terus mengupayakan koordinasi dengan pihak terkait guna untuk melanjutkan kelancaran realisasi pembangunan ke depannya. Dalam perencanaan tersebut, didukung dengan pernyataan pengelola diuraikan dalam kutipan sebagai berikut :

"Sementara ini fokus pengajuan anggaran untuk akses dulu, biar mudah dilalui pengunjung".

Berdasarkan pernyataan
pengelola dalam perencanaan
pembangunan yang akan dibangun pengelola yaitu akses jalan yang rencananya dibagi menjadi dua rute yaitu :

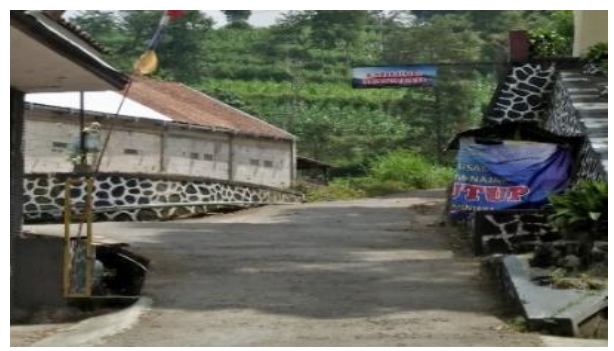

Gambar 10 Akses Menuju Embung Dokumentasi Pribadi

- Akses dekat pusat oleh-oleh Mbah Jadah

Merupakan akses saat ini yang digunakan pengunjung menuju lokasi objek dan hanya bisa dilalui kendaraan motor. Rencananya akan dilakukan pelebaran jalan guna untuk memudahkan pengunjung menuju lokasi.

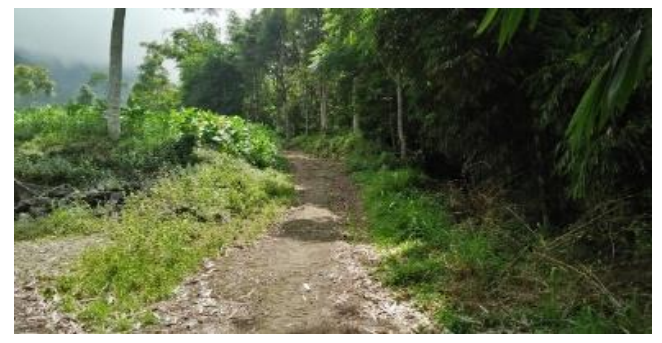

Gambar 11 Akses Menuju Embung Dokumentasi Pribadi

- Akses melalui Goa Raja

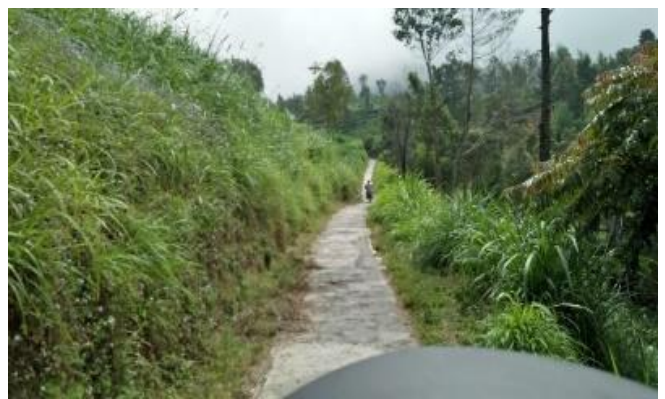

Gambar 12 Akses Menuju Embung Dokumentasi Pribadi

Merupakan akses yang digunakan untuk membawa material pembangunan embung. Lebar jalan ini sekitar 2,5 meter, sehingga rencananya akses ini dapat digunakan pengunjung yang membawa kendaraan mobil.

\section{Ancillary Service}

Tentunya keberadaan organisasi dalam pengelolaan destinasi mempengaruhi kualitas pelayanan yang diberikan kepada pengunjung. Pengaruh organisasi ini dapat digunakan untuk meningkatkan kepuasan wisatawan. Salah satunya meningkatkan kualitas sumber daya manusia untuk bersikap selalu ramahtamah (hospitallity) dan mendengarkan permintaan atau kebutuhan wisatawan. Pariwisata merupakan trade in services atau perdagangan jasa kepada wisatawan, 
sehingga kegiatan pariwisata tidak dapat terlepas dari peran masyarakat itu sendiri sebagai tuan rumah. Hal tersebut berkaitan dengan pendapat (Moscardo, 2020) bahwa hampir setiap tahun, elemen pariwisata memerlukan sumber daya manusia untuk menggerakkannya. Sebagai salah satu industri jasa, sikap serta kemampuan staf akan berdampak penting pada pelayanan pariwisata yang diberikan kepada wisatawan yang akan berdampak secara langsung pada kenyamanan, kepuasan serta kesan atas kegiatan wisata yang dilakukannya.

Dengan begitu, masyarakat diharapkan untuk dapat memiliki skill serta pengetahuan mengenai bidang pariwisata agar mampu mengawal dan menciptakan ide kreatif dalam keberlangsungan kegiatan pariwisata, sekaligus memberikan excellent services kepada wisatawan. Menurut data Kelurahan Samiran (https://desasamiran.id/), tercatat bahwa lulusan SDM pada tingkat SD atau sederajat sebanyak $41,35 \%$. Artinya SDM yang ada saat ini sangat rendah karena mayoritas lulusan SD atau sederajat. Lebih lanjut mayoritas mata pencaharian masyarakat Desa Samiran adalah pertanian atau perkebunan sebanyak 44,99\%. Hal tersebut menunjukkan bahwa perlu ada beberapa alternatif untuk meminimalisir kelemahan SDM masyarakat sekitar :

1. Pertama, yaitu adanya sosialisasi dan penyuluhan terkait sadar wisata.

2. Kedua, yaitu pengembangan SDM melalui pendidikan informal seperti adanya pelatihan bahasa asing, hospitality, pemandu wisata (guide lokal), dsb.
3. Ketiga, melaksanakan sertifikasi pramuwisata yang diselenggarakan oleh Gubernur. Pramuwisata hendaknya memiliki sertifikasi kompetensi agar dapat meningkatkan pelayanan kepada wisatawan dan telah diatur dalam Perda no. 14 tahun 2016.

Berdasarkan hasil observasi dan wawancara, wisata Embung Manajar ini belum memiliki kelembagaan secara khusus untuk mengelola, karena belum adanya jalinan kerjasama dengan pemerintah khususnya dinas pariwisata maupun para stake holder. Sehingga objek wisata Embung Manajar ini masih dikelola secara mandiri oleh masyarakat Desa Samiran dan dalam pengelolaannya belum terorganisir dengan baik.

\section{KESIMPULAN DAN SARAN Kesimpulan}

Atraksi yang terdapat di Embung Manajar yaitu nature resources (alami) adalah pemandangan alam Gunung Merapi, terdapat banyak sekali atraksi yang bisa dilakukan oleh pengunjung salah satunya adalah berfoto selfie dengan pemandangan embung dan Gunung Merapi. Dengan adanya atraksi yang ada di Embung Manajar ini diharapkan dapat menambah obyek wisata baru di Kabupaten Boyolali dan diharapkan juga dapat menambah perekonomian warga di sekitar. Amenitas yang terdapat di Embung Manajar belum lengkap dan masih memerlukan perbaikan dan penambahan fasilitas lainnya yang dapat mendukung kenyamanan pengunjung ataupun wisatawan. aksesbilitas di Embung Manajar masih memerlukan perbaikan guna untuk mendukung kemudahan 
pengunjung menuju lokasi. Ancillary services dalam pengelolaan wisata Embung Manajar ini masih memerlukan peningkatan SDM melalui penyuluhan sadar wisata, pengembangan SDM melalui pendidikan informal, dan sertifikasi pramuwisata.

\section{DAFTAR PUSTAKA}

Abdulhaji, S., \& Yusuf, I. S. H. (2016). Pengaruh Atraksi, Aksesibilitas, dan Fasilitas Terhadap CItra Objek Wisata Danau Tolire Besar Di Kota Ternate. 7(2).

Ariningsiha, I. G. A. A., \& Nugrohoa, S. (2015). Pelestarian Unit Pelaksana Teknis Dinas (UPTD) Museum Subak sebagai Daya Tarik Wisata Budaya di Kabupaten Tabanan. Jurnal Destinasi Pariwisata ISSN, $2338,8811$.

Kurniawati, O. (2019). Diferensiasi terhadap Atraksi Wisata Budaya Grebeg Sudiro di Kelurahan Sudiroprajan Kota Solo Tahun 2017-2019.

Mauludin, R. (2017). Pengaruh Atraksi Wisata Terhadap Minat Berkunjung Wisatawan Ke Daya Tarik Wisata Waduk Darma Kabupaten Kuningan. Jurnal Manajemen Resort Dan Leisure, 14(2), 57-68. https://doi.org/10.17509/jurel.v14i2. 9241

Moscardo, G. (2020). Stories and design in tourism. Annals of Tourism Research, 83(January), 102950. https://doi.org/10.1016/j.annals.2020 .102950

Nundy, S., Ghosh, A., Mesloub, A., Albaqawy, G. A., \& Alnaim, M. M. (2021). Impact of COVID-19 pandemic on socio-economic, energy-environment and transport sector globally and sustainable development goal (SDG). Journal of
Cleaner Production, 127705.

Pradipta, M. P. Y. (2018). Pengembangan Wisata Alternatif Sebagai Strategi Dalam Pengembangan Agrowisata di Desa Tretes Kecamatan Selo Kabupaten Boyolali. Jurnal Pariwisata Indonesia, 14(1), 80-93.

Pradipta, M. P. Y. (2021). Pariwisata Berbasis Masyarakat Sebagai Pelestari Tradisi Di Desa Samiran. Jurnal Kepariwisataan, 5(1), 99109.

https://doi.org/10.34013/jk.v5i1.379

Pradipta, M. P. Y., Suprapto, M. H., \& Purnomo, B. (2018). Peran Kelompok Sadar Wisata Dalam Merevitalisasi Kampung Pecinan Sebagai Objek Dan Daya Tarik Wisata di Kota Surakarta. Jurnal Pariwisata Indonesia, 14(1), 60-65.

Rif'an, A. A. (2018). Daya Tarik Wisata Pantai Wediombo Sebagai Alternatif Wisata Bahari Di Daerah Istimewa Yogyakarta. Jurnal Geografi, 10(1), 63.

https://doi.org/10.24114/jg.v10i1.79 55

Steves, F., Treisman, D., \& Teytelboym, A. (2011). The political economy of climate change policy in the transition region. The Low Carbon Transition.

Terzidou, M. (2020). Re-materialising the religious tourism experience: A posthuman perspective. Annals of Tourism Research, 83(April), 102924.

https://doi.org/10.1016/j.annals.2020 .102924

Valentina, V. (2015). Heritage as an Alternative Driver for Sustainable Development and Economic Recovery in South East Europe. Procedia - Social and Behavioral Sciences, 188, 1-2. https://doi.org/10.1016/j.sbspro.2015 .03 .332

Zheng, W., Huang, L., \& Lin, Z. (2021). Multi-attraction, hourly tourism demand forecasting. Annals of 


\section{Sabbhata Yatra}

Jurnal Pariwisata dan Budaya

Volume 2 Nomor 2 Desember 2021

Tourism Research, 90, 103271.

https://doi.org/10.1016/j.annals.2021

.103271 